\title{
VORSCHAU $01>$
}

\section{ENTWICKLUNG}

Der neue v8-Ottomotor von BMW mit zwei Turboladern, Direkteinspritzung und vollvariablem Ventiltrieb

\section{Identifikation und Bewertung \\ des Ölverbrauchs bei \\ transientem Motorbetrieb}

\section{FORSCHUNG}

Das aktive Motorlagerungs-System im neuen Audi S8

\section{Maßnahmen zur Geräuschoptimierung künftiger Pkw-Dieselmotoren}

Die Entwicklung der Abgasanlage des Mercedes-Benz SL

\section{Motornahe Abgasenergierekuperation bei einem Ottomotor}

Schadstoffreduzierung durch Diesel-Wasser-Emulsionen
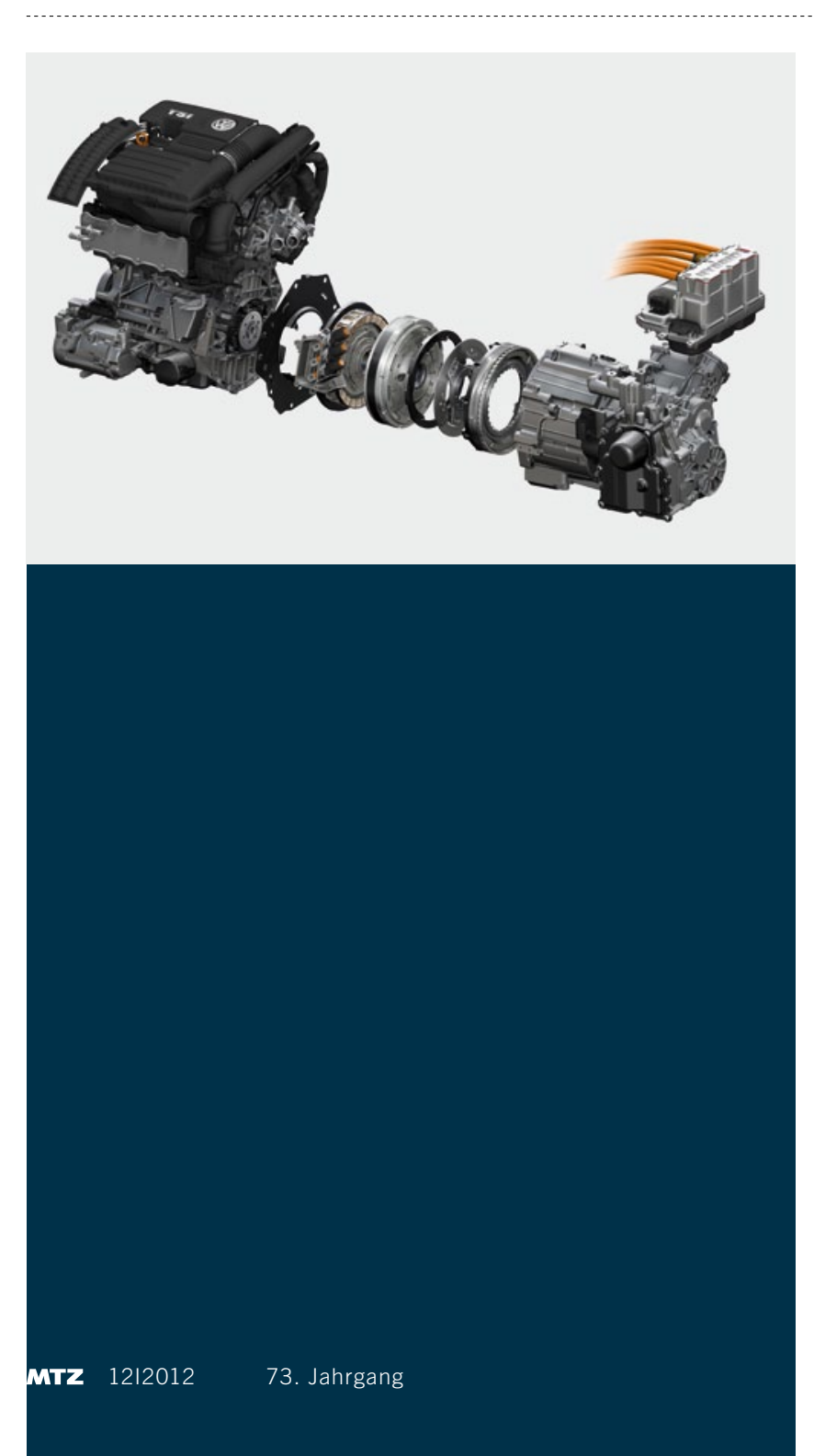

\section{TITELTHEMA}

\section{ENERGIEMANAGEMENT}

Zur weiteren Reduzierung der $\mathrm{CO}_{2}$-Emissionen gilt es, die unvermeidlichen Verluste bei der Umwandlung der Energie vom Tank bis zum Rad möglichst gering zu halten. Damit kommt dem bedarfsgerechten und effizienten Management der Energieströme künftig immer höhere Bedeutung im Entwicklungsprozess zu. Gerade bei Hybridfahrzeugen oder Elektroautos mit Range Extender, bei denen mechanische und elektrische Energie zur Verfügung stehen, ist eine optimale Abstimmung der Energieströme von zentraler Bedeutung, um die theoretischen Vorteile der Systeme in die Praxis zu übertragen. Aber auch beim konventionellen Antrieb mit Verbrennungsmotor bieten Energiemanagement-Maßnahmen noch großes Einsparpotenzial, beispielsweise Systeme zur Wärmeenergiespeicherung und -nutzung oder zur Bremsenergierückgewinnung.

Volkswagen stellt in der nächsten MTZ den Antriebsstrang und die Betriebsmodi des neuen Jetta Hybrid vor. Die Komponenten sind Teil eines skalierbaren, modularen Baukastens und können auch in weiteren Projekten des Konzerns eingesetzt werden. Wie Behr zeigt, werden Emissionen und Verbrauch beim Kaltstart des Verbrennungsmotors mit einem Enthalpiespeicher erheblich reduziert. Fahrzeuguntersuchungen weisen ein $\mathrm{CO}_{2}$-Einsparpotenzial des neuen Behr-Systems von mehr als $1,5 \%$ in NEFZ aus. Welche Möglichkeiten zur $\mathrm{CO}_{2}$-Reduzierung das Energiemanagement künftig aus Sicht von Continental bietet, skizziert José Avila, Leiter der Division Powertrain und Mitglied des Vorstands der Continental AG, im Interview mit der MTZ. 